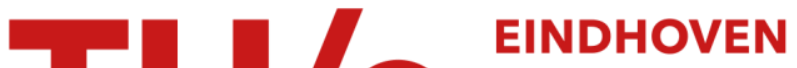 UNIVERSITY OF TECHNOLOGY
}

\section{Long, lifetime, triggered, spark-gap switch for repetitive pulsed power applications}

\section{Citation for published version (APA):}

Winands, G. J. J., Liu, Z., Pemen, A. J. M., Heesch, van, E. J. M., \& Yan, K. (2005). Long, lifetime, triggered, spark-gap switch for repetitive pulsed power applications. Review of Scientific Instruments, 76(8), 085107-1/6. https://doi.org/10.1063/1.2008047

DOI:

10.1063/1.2008047

Document status and date:

Published: 01/01/2005

\section{Document Version:}

Publisher's PDF, also known as Version of Record (includes final page, issue and volume numbers)

\section{Please check the document version of this publication:}

- A submitted manuscript is the version of the article upon submission and before peer-review. There can be important differences between the submitted version and the official published version of record. People interested in the research are advised to contact the author for the final version of the publication, or visit the $\mathrm{DOI}$ to the publisher's website.

- The final author version and the galley proof are versions of the publication after peer review.

- The final published version features the final layout of the paper including the volume, issue and page numbers.

Link to publication

\section{General rights}

Copyright and moral rights for the publications made accessible in the public portal are retained by the authors and/or other copyright owners and it is a condition of accessing publications that users recognise and abide by the legal requirements associated with these rights.

- Users may download and print one copy of any publication from the public portal for the purpose of private study or research.

- You may not further distribute the material or use it for any profit-making activity or commercial gain

- You may freely distribute the URL identifying the publication in the public portal.

If the publication is distributed under the terms of Article 25fa of the Dutch Copyright Act, indicated by the "Taverne" license above, please follow below link for the End User Agreement:

www.tue.nl/taverne

Take down policy

If you believe that this document breaches copyright please contact us at:

openaccess@tue.nl

providing details and we will investigate your claim. 


\title{
Long lifetime, triggered, spark-gap switch for repetitive pulsed power applications
}

\author{
G. J. J. Winands, ${ }^{\text {a) }}$ Z. Liu, A. J. M. Pemen, E. J. M. van Heesch, and K. Yan \\ EPS Group, Department of Electrical Engineering, Eindhoven University of Technology, $5600 \mathrm{MB}$, \\ Eindhoven, The Netherlands
}

(Received 29 April 2005; accepted 1 July 2005; published online 4 August 2005)

\begin{abstract}
In this article a critical component for pulsed power applications is described: the heavy-duty switch. The design of a coaxial, high repetition rate, large average power, and long lifetime spark-gap switch is discussed. The switch is used with a fail-free $L C R$ trigger circuit. Critical issues for switch design are presented together with experimental results. It is observed that the switch has a good stability, and its lifetime is estimated to be in the order of $10^{10}$ shots $\left(\sim 10^{6} \mathrm{C}\right)$ at $10 \mathrm{~J} / \mathrm{pulse}$, $60 \mathrm{kV}$ and $100 \mathrm{~ns}$ pulses. Measurements were performed with 20 and $34 \mathrm{kV}$ average switching voltage (100 ns pulses, energy per pulse 0.4 and $0.75 \mathrm{~J}$, respectively). For up to 450 pulses/s (pps), pre-firing can be prevented by increasing the gap pressure (up to 2.5 and 7 bars, respectively), no gas flush is required. Above $450 \mathrm{pps}$, up to $820 \mathrm{pps}$, a forced gas flow of maximal $35 \mathrm{Nm}^{3} / \mathrm{h}$, is required for stable operation. Measurements on the time delay and jitter of the switch demonstrate that these values are influenced by pressure, flow, and pulse repetition rate. For $34 \mathrm{kV}$ average switching voltage the time delay and time jitter vary between 35 and 250 and 10 and $80 \mu \mathrm{s}$, respectively. For $20 \mathrm{kV}$ average switching voltage these values are: $30-160$ and $4-50 \mu \mathrm{s}$. During a test run of $2.5 \mathrm{~h}$ (at $100 \mathrm{~Hz}, 0.75 \mathrm{~J} /$ pulse) the feasibility of the switch was proved, and the switching voltage jitter was less than 0.7\%. (C) 2005 American Institute of Physics.
\end{abstract}

[DOI: $10.1063 / 1.2008047$ ]

\section{INTRODUCTION}

For pulsed power applications, the heavy-duty switch is usually the most critical component. Several types of closing switches are available like: ${ }^{1}$ insulated gate bipolar transistor (IGBT), transistors, thyristors, thyratrons and spark-gap switches (gas, liquid). For spark-gap switches a general classification can be made into switches with fixed electrodes and switches with rotating electrodes. The first category can be further divided into self-triggered switches and forced triggered switches.

For large scale pulsed power applications using ultrashort nanosecond pulses, spark-gap switches are usually used. Also, solid state switches followed by magnetic pulse compression stages are sometimes adopted. The main disadvantage of magnetic pulse compression is the low energy efficiency for ultrashort pulses (20-50 ns). For spark-gap switches the lifetime was the mayor limiting factor. Other shortcomings with spark gaps are related to: limited pulse repetition rate, strong electrode erosion, insulator degradation, high arc inductance, limited hold-off voltage, and costly triggering.

In this article, a newly developed coaxial spark-gap switch having large, fixed, brass, electrode surfaces is described. Because of the design of the electrodes, a long lifetime can be guaranteed. The coaxial structure ensures a low inductance and containment of possible hazardous electro

\footnotetext{
${ }^{a)}$ Author to whom correspondence should be addressed; electronic mail:
} g.j.j.winands@tue.nl magnetic interference (EMI) radiation. This spark gap is pressurized and continuously flushed with air to increase pulse repetition rate, to remove spark residue from the gap, and to cool down the electrodes. For reliable switching behavior, the switch is used with an $L C R$ trigger circuit. When operated in a correct regime, the $L C R$ circuit always causes the switch to close at the right moment.

\section{SPARK-GAP SWITCH DESIGN}

The goal of our research was to construct a pulsed power source for pulsed corona plasma applications ${ }^{2-5}$ with output characteristics as mentioned in Table I. As discussed below, a high-pressure coaxial-type spark-gap switch was considered as the most suitable one to match the tasks. Figure 1 shows schematic overviews of the designed coaxial spark-gap switch. The general characteristics of the switch are summarized in Table II. During the design of the switch, the following remarks were taken into account:

For an un-flushed spark-gap switch, the typical recovery time is in the millisecond range. ${ }^{6-8}$ Pulse repetition rates typically will remain below 200 pps. The time between pulses is needed to remove the residue of the preceding arc from the electrode gap and to restore both gas temperature and density. ${ }^{9}$ If the switch is charged before the gap conditions have been restored, the switch may pre-fire, i.e., close before the maximum charging voltage is obtained. To obtain higher repetition rates, several possibilities exist like the use of high-pressure hydrogen, ${ }^{10,11}$ electrostatic sweep of the electrode gap, ${ }^{8}$ corona stabilization, ${ }^{12}$ using nonlinear $V$ - $p$ 
TABLE I. Pulsed power source output characteristics and requirements.

\begin{tabular}{lc}
\hline \hline Switching voltage & $<60 \mathrm{kV}$ \\
Switching current & $<5 \mathrm{kA}$ \\
Pulse repetition rate & $1-1000 \mathrm{pps}$ \\
Pulse rise time & $<20 \mathrm{~ns}$ \\
Pulse width & $<100 \mathrm{~ns}$ \\
Energy per pulse & $<10 \mathrm{~J}$ \\
\hline \hline
\end{tabular}

effects, ${ }^{8}$ and flushing the gap with a forced gas flow. ${ }^{4}$ The latter option was chosen for our spark-gap design. Dry air was chosen as flush gas. Besides the ability to increase the pulse repetition rate, the flow ensures additional cooling of the electrodes and removal of the arc residue and eroded electrode material from the switch. This way, surface flashover on the high-voltage feedthrough insulators, as a result of conducting material deposition, is prevented. Possible damage to the insulator surface due to radiation of the spark is limited as a result of the small opening angle (Fig. 1) of the radiation originating from the electrode-trigger gap.

To generate a very short pulse, it is important to keep the inductance of the switch as small as possible. In Ref. 13 it was shown that by decreasing the gap distance, the inductance of the switch decreases. To prevent pre-firing of the switch when the distance is reduced, the spark-gap switch has to be pressurized. Besides a reduction in inductance this also results in a decrease of arc resistance. For our present design, the minimum distance of the electrodes was limited to $2 \mathrm{~mm}$.

The distance between the electrodes and the maximal pressure determines the maximum operating voltage of the switch. For the coaxial spark gap, the voltage difference between anode and trigger and that between trigger and cathode will be close to half the switching voltage (see discussion on LCR circuit, below), during the charging of the energy storage capacitor $C_{h}$ [Fig. 1(b)]. Because the switch is pressurized with dry air up to 7 bars, and the gap distances between electrodes are $2 \mathrm{~mm}$, maximum operating voltage is about $75 \mathrm{kV}$. However, to prevent partial discharges and breakdowns on the input and output connections of the switch, the voltage will be limited to approximately $60 \mathrm{kV}$.

To guarantee a long lifetime of the switch, two approaches can be used. The first one is to increase the amount of electrode material allowed to evaporate. For the coaxial spark-gap switch a large volume of electrode material is indeed allowed to evaporate before the gap distance becomes too large for proper switching. Especially, the triggerelectrode surface is large. Even when a layer of the electrode material is evaporated, the switch can still be used, simply by decreasing the pressure. ${ }^{4}$ The second approach is to ensure little evaporation per shot. This can be accomplished by a good material choice or by minimizing energy transfer per shot, for example, by using several switches in parallel. ${ }^{4}$ As a result of data found in literature, ${ }^{12,14,15}$ brass was chosen as electrode material since the erosion rate is low compared to other materials and the material is cheap. The "moving arc" principle $^{15}$ can also ensure reduced evaporation per shot since for moving arcs the hot-spot temperature and thus the evaporation rate decreases. Due to the coaxial construction, the moving arc principle also plays an important role in the present design. As a result of magnetic pinching, any arc initiated between the electrodes will start moving towards the center of the switch. The arc is thus not confined to one spot, but moves along the surface. Another important aspect related to the lifetime is the matching between the source and the load. ${ }^{4}$ In case of a not properly matched system, part of the pulse energy will be reflected back from the load. This energy is partly dissipated in the spark-gap switch, causing additional erosion of the electrodes. To reduce electrode wear it is thus important to optimize the matching of the complete system. For the present switch, its coaxial structure gives roughly an impedance of $25 \Omega$ during switching, which is matched to both a pulse forming line and a two stage transmission line transformer. ${ }^{4}$ This way, both the switch inductance and switch lifetime can be improved.

Generally speaking, evaporation of electrode material not only influences the lifetime of the switch, but also leads to enhanced roughness of the electrode surface. As a result, the hold-off voltage of the switch would decrease. However, as shown on the photograph in Fig. 8, the electrode erosion for the coaxial spark-gap switch is very uniform. The switch is closed randomly along the electrode surface and the arc moves towards the center. As a result, the hold-off voltage does not decrease.

For stable operation of the pulsed power source, the switch has to be closed just after the charging process. For an un-triggered switch, the closing usually has a very unstable, statistical behavior. The voltage difference between anode
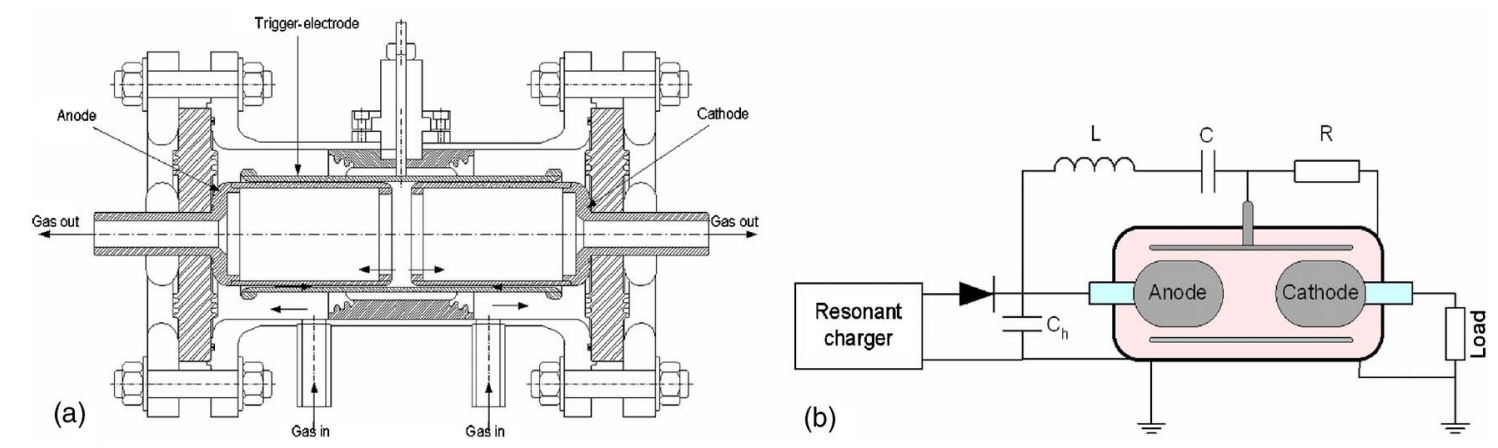

FIG. 1. (a) Construction drawing of the coaxial spark-gap switch. The arrows in the bottom part indicate the direction of the flow. (b) Schematic representation of the switch, connected to the charging unit and $L C R$ trigger. 
TABLE II. Characteristics of the coaxial spark-gap switch.

\begin{tabular}{lcccc}
\hline \hline & & & \\
Anode/cathode & Material & Brass & Anode-trigger & $2 \mathrm{~mm}$ \\
& Length & $114 \mathrm{~mm}$ & distance & \\
& Diameter & $61 \mathrm{~mm}$ & Max. pressure & $7 \mathrm{bar}$ \\
Trigger & Material & Brass & Max. flow rate & $35 \mathrm{Nm}^{3} / \mathrm{h}$ \\
electrode & Length & $202 \mathrm{~mm}$ & Line impedance & $25 \Omega$ \\
& Diameter & $65 \mathrm{~mm}$ & Repetition rate & $<1 \mathrm{kpps}$ \\
Ground & Material & Stainless & Switching & $\sim 60 \mathrm{kV}$ \\
structure & Steel & voltage & \\
& Length & $252 \mathrm{~mm}$ & Average power & $\sim 10 \mathrm{~kW}$ \\
& Diameter & $108 \mathrm{~mm}$ & & \\
\hline \hline
\end{tabular}

and cathode directly after charging has to be matched to the breakdown voltage of the gap. Due to the statistical behavior of spark generation, pre-firing and very late firing often occur (Fig. 2). Pre-firing decreases the average switching voltage, and thus a decrease of the energy. Late firing implies longer stress period on the high-voltage components, and limits the pulse repetition rate. Stable operation can be obtained by triggering the switch at the right moment. Several possibilities exist for triggering the switch, such as by using a laser beam or by using an external triggering voltage pulse. For the present switch and circuit design, the triggering is performed with an $L C R$ circuit, see below, which is based on overvoltage generation between the electrodes after the charging is completed.

\section{LCR-TRIGGER METHOD AND SWITCH OPERATION}

To explain the operation mechanism of the switch, it is preferable to start with the principle of the $L C R$ trigger circuit. To illustrate the mechanism of the implemented $L C R$ trigger method the following equations are useful. The work of $\mathrm{Yan}^{4}$ can be used to obtain the complete circuit of the resonant charging unit. The storage capacitor $C_{h}$ is resonantly charged by the charging circuit. The charging voltage $V$ on the anode can be expressed as

$$
V(t)=\frac{V_{\max }}{2} \cdot\left[1-\cos \left(\omega_{2} \cdot t\right)\right],
$$

where $V_{\max }$ is the maximum voltage on $C_{h}$ and $\omega_{2}$ is the resonant charging frequency of the source. During the charging of $C_{h}$, the voltage $V_{T}$ on the trigger electrode changes as

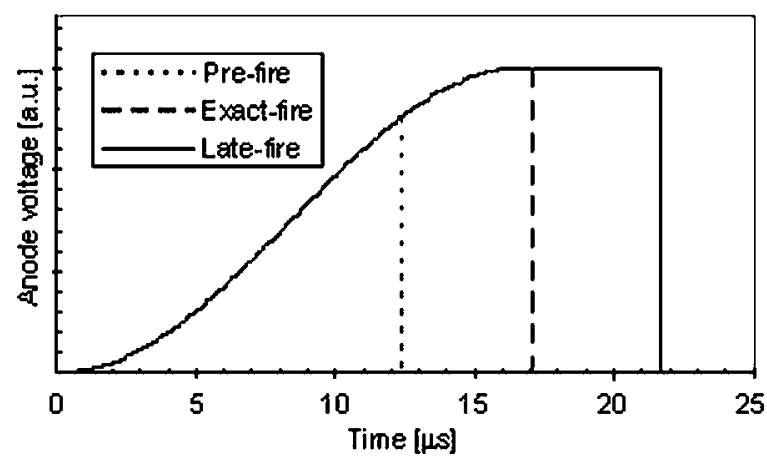

FIG. 2. Firing modes of a spark-gap switch. The voltage on $C_{h}$ [Fig. 1(b)] is shown.

$$
\begin{aligned}
V_{T}(t)= & \frac{V_{\max }}{2} \cdot \frac{\omega_{2}^{2} \cdot \tau_{L C R}^{2}}{1+\omega_{2}^{2} \cdot \tau_{L C R}^{2}} \cdot\left(\exp \left(-\frac{t}{\tau_{L C R}}\right)\right. \\
& \left.-\cos \left(\omega_{2} \cdot t\right)\right)+\frac{V_{\max }}{2} \cdot \frac{\omega_{2} \cdot \tau_{L C R}}{1+\omega_{2}^{2} \cdot \tau_{L C R}^{2}} \cdot \sin \left(\omega_{2} \cdot t\right),
\end{aligned}
$$

where $\tau_{L C R}=R \cdot C$ is the time constant of the trigger circuit. The value of $\tau_{L C R}$ determines the voltage ratio $V_{T}(t) / V(t)$ after charging of $C_{h}\left(t=\pi / \omega_{2}\right)$. In Fig. 3, the voltages on anode and trigger electrodes are plotted as function of time.

Since resonant charging is used as the basic mechanism for energy storage in the high-voltage capacitor, the voltage on the switch will rise as a cosine function. The voltage on the trigger electrode also rises as a cosine function, only with lower amplitude and some time delay. Once the charging process is finished, the voltage on the anode remains constant (as long as $C_{h} \gg C$ ), but the voltage on the trigger electrode will decrease with time constant $\tau_{L C R}$. As a result the voltage difference between anode and trigger increases, leading in the end to an arc plasma in the $L-C$-anode-trigger gap circuit. The energy stored in $C$ is now dissipated in the anode-trigger gap, supplying sufficient energy to sustain the spark. Typical energy dissipation in the arc is in the order of several $\mathrm{mJ}$. As a result of the closure of the anode-trigger gap, the voltage difference between trigger and cathode rises drastically. As a result of this large overvoltage and the UV light generated in the anode-trigger gap, the trigger-cathode gap will close almost immediately. Now the anode and cath-

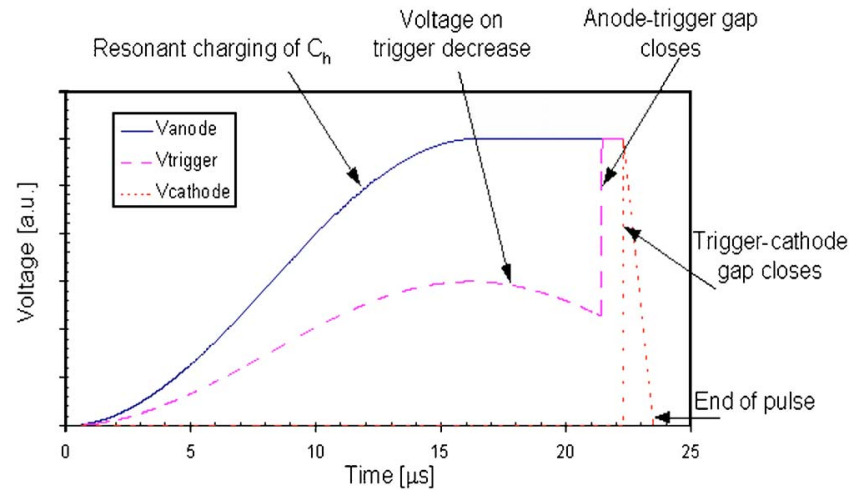

FIG. 3. (Color online). Schematic representation of the voltages on the anode, cathode and trigger electrode. For clarity, the pulse length $\left(V_{\text {cathode }}\right)$ is drawn about ten times longer than the one mentioned in Table I. 


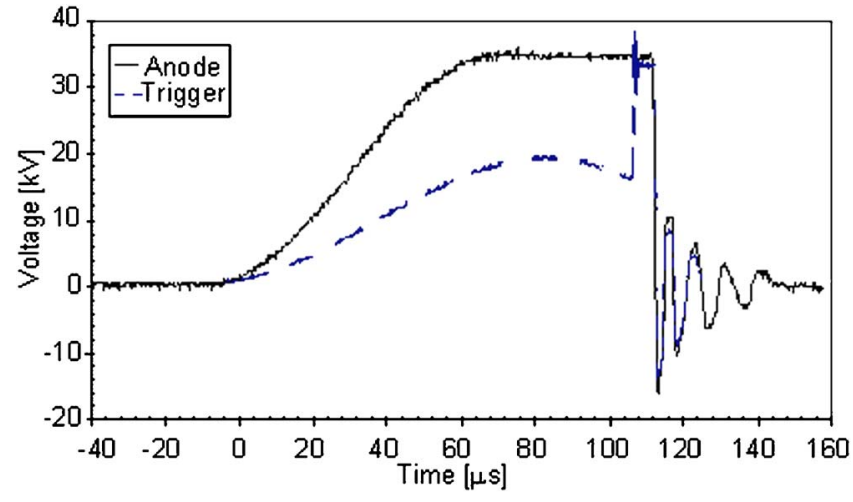

FIG. 4. (Color online). Typical voltage wave forms on the anode and trigger electrode.

ode are electrically connected via the trigger electrode, i.e., the switch is closed. The trigger method is independent of electrode geometry and charging voltage. If the switch is operated in a correct $V$ - $p$ regime, the switch will always fire, due to the ever increasing voltage difference between the anode and trigger electrode.

Because of the layout of the coaxial spark-gap switch, it is important that during charging the voltage difference between anode and trigger, and that between cathode and trigger, are equal to each other. Otherwise the switch could prefire. Due to the switch design, this means that the maximum
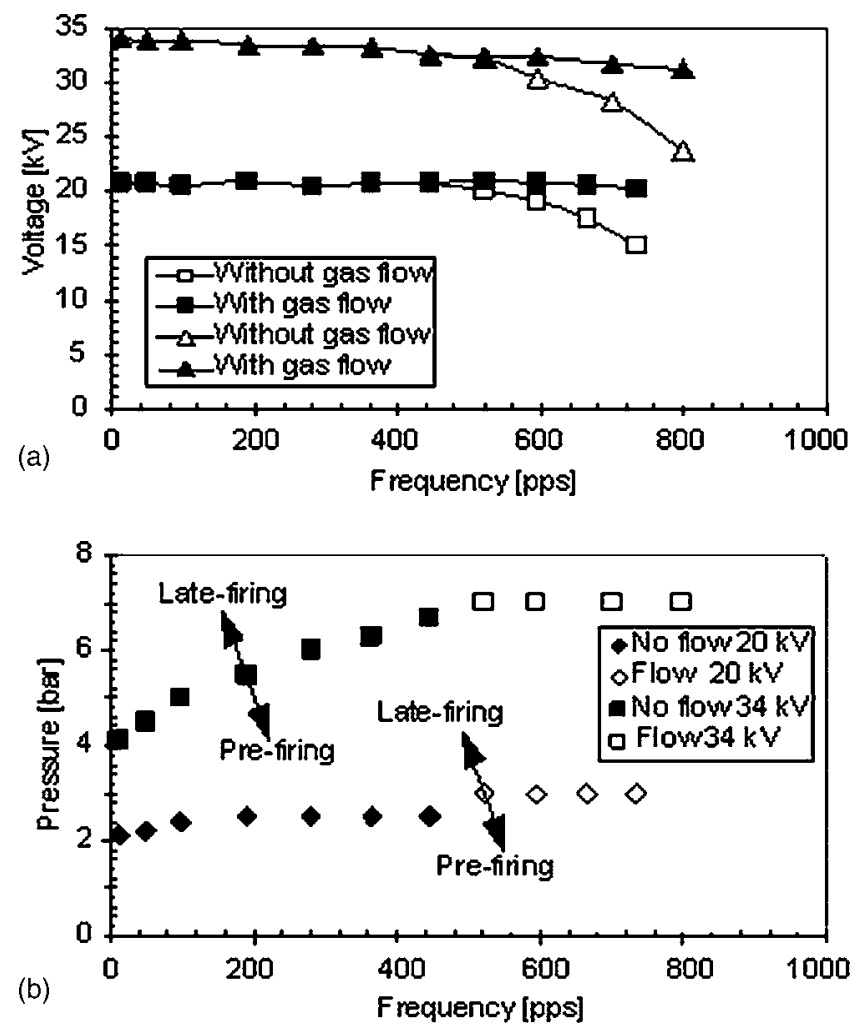

FIG. 5. (a) Average switching voltage as function of pulse repetition rate. Two different charging voltages were used: 20 and $34 \mathrm{kV}$. (b) Pressurepulse repetition rate dependence for stable switch performance. Above $450 \mathrm{pps}$, flow was also needed to prevent pre-firing, see Fig. 6. The markers indicate the operating conditions at the limit between pre-firing and late firing, for a specific average switching voltage.

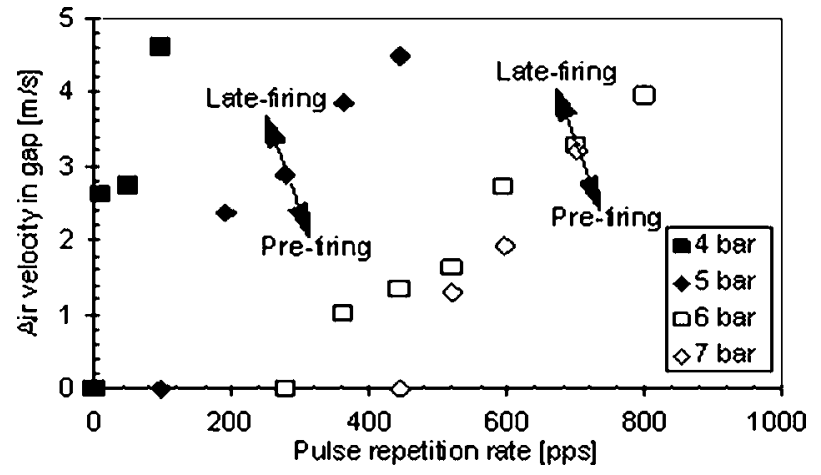

FIG. 6. Required air velocity and pressure, for stable switching performance, as function of pulse repetition rate at $34 \mathrm{kV}$ average switching voltage. The pulse repetition rate $(<820 \mathrm{pps})$ was limited by the charging unit. The markers indicate the operating conditions at the limit between pre-firing and late-firing, for a specific pressure.

voltage on the trigger electrode should be $50 \%$ of the anode voltage. The voltage on the trigger electrode can be adjusted by changing the components of the $L C R$ trigger circuit.

\section{EXPERIMENTAL RESULTS AND DISCUSSION}

Experiments were performed at two different average switching voltages: 20 and $34 \mathrm{kV}$. In the near future the resonant charging circuit will be equipped with a new pulse transformer, enabling measurements with voltages up to $60 \mathrm{kV}$. The pulse width of the generated pulses was about $100 \mathrm{~ns}$ [full width at half maximum (FWHM)], energy per pulse was 0.4 and $0.75 \mathrm{~J}$ for the different voltages. For all the measurements the voltage ratio $V_{T}(t) / V(t)$ after charging of $C_{h}$ was fixed to $50 \%$. To be able to measure at high pulse repetition rates, a resistive load could not be used. Instead, a wire-plate corona reactor was used. In general, due to some impedance mismatch between source and reactor, part of the energy reflects back towards the source. This way the recovery time of the switch becomes longer in comparison with a matched resistive load, i.e., when no energy is reflected.

In Fig. 4, typical voltage wave forms on the anode and trigger electrode can be seen, which are in agreement with the theoretically derived ones as shown in Fig. 3. The oscillations after switch closing are due to impedance mismatch between source and load.

\section{A. Operating regimes for stable trigger performance}

Measurements concerning the voltage, pressure, pulse repetition rate, and dry air flow rate are shown in Figs. 5 and 6. Each marker in the plots is the result of averaging over 1000 shots. Figure 5(a) shows the average switching voltage as function of pulse repetition rate. Looking at the line "with gas flow, $34 \mathrm{kV}$ " a small decrease of the average voltage as function of pulse repetition rate can be seen. This was due to the charging unit, not to the switch. To be able to compare between the obtained results it is preferable to eliminate the source influence. During the measurements this was realized by slightly decreasing the input voltage of the source for lower frequencies.

For both 20 and $34 \mathrm{kV}$, up to $\sim 450$ pps no gas flow was needed to prevent pre-firing, only the pressure inside the gap 

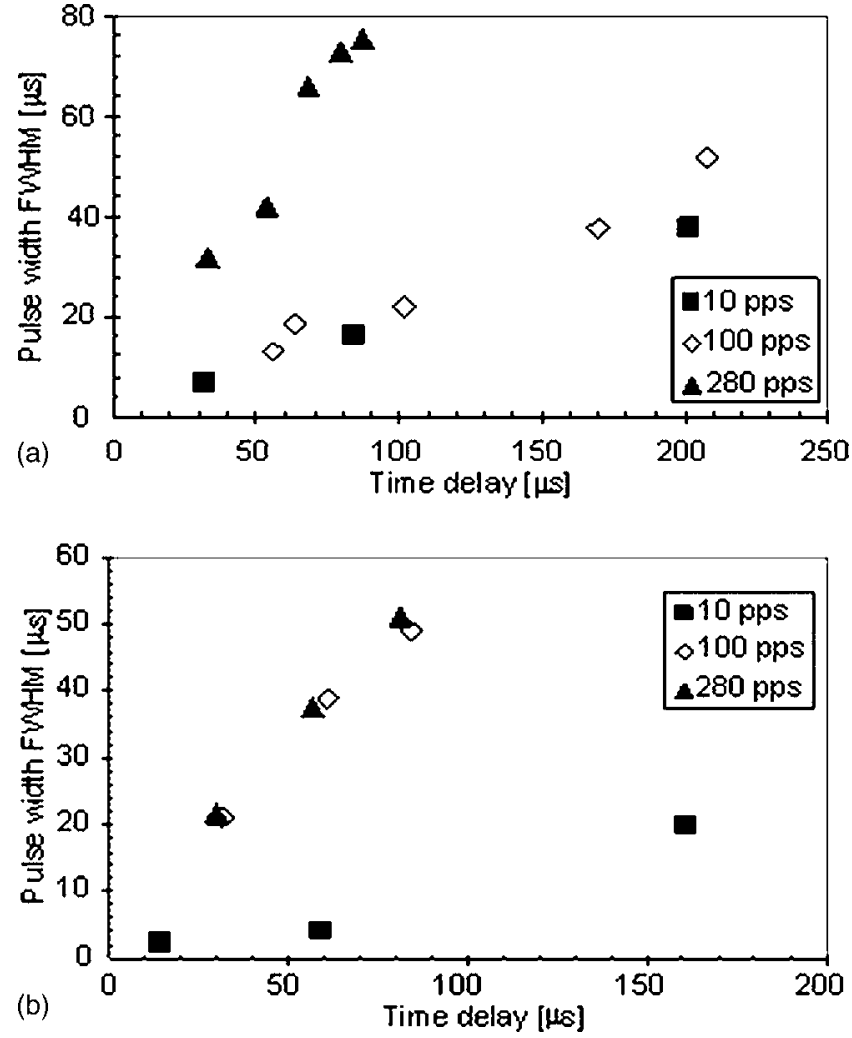

FIG. 7. Jitter as function of time delay and pulse repetition rate. (a) Average switching voltage $34 \mathrm{kV}$, (b) average switching voltage $20 \mathrm{kV}$.

had to be increased [Fig. 5(b)]. Whether or not the switch was pre-firing was determined by measuring the average switching voltage. For a given pressure and gas flow rate, the measured average switching voltage was compared with the maximal attainable value (optimized pressure and flow rate). A smaller switching voltage indicates pre-firing occurs. Apparently, the increased pressure improves the recovery time of the switch. The typical design of the coaxial spark-gap switch, together with the $L C R$ trigger method, enables operation over a broad pressure range. For example, when switching $34 \mathrm{kV}$ pulses, the pressure can be in between 4 and 7 bars.

In general it can be stated that the obtained recovery time of $\sim 2 \mathrm{~ms}$, for an un-flushed switch, is very short compared to the work reported earlier by other authors. ${ }^{6-8}$ The exact reason for this short recovery time is not completely understood at this moment, but it is believed that it is due to the combination of low energy transfer per pulse, short gap distances and large electrode surfaces. The electrodes act as heat sink, quickly restoring the gas temperature to the initial temperature. Ions generated during the spark move to the electrodes in a shorter period because of the short distance.

Besides stabilizing the switch by means of increasing the pressure, the spark-gap switch can also be stabilized by increasing the gas-flow rate. Instead of using the output airflow rate as measure it was chosen to look at the effects of the absolute air velocity inside the spark gap. The air velocity was determined using

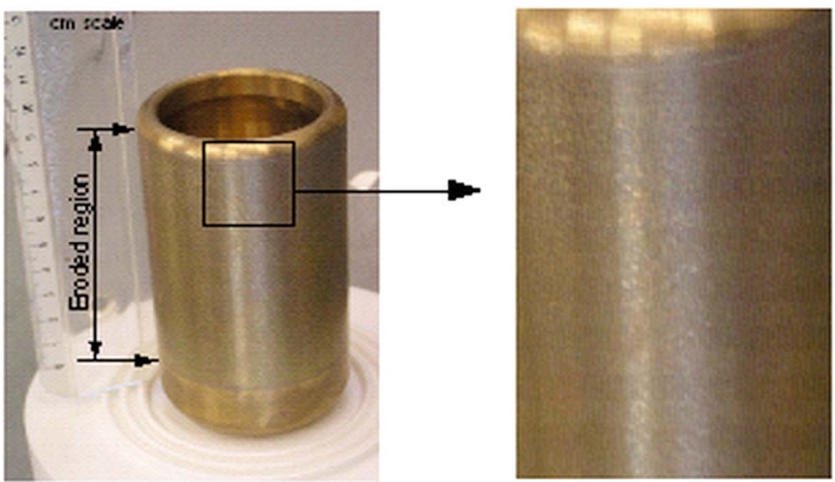

FIG. 8. (Color online). Photographs showing the uniform erosion on one of the electrodes. The photograph was taken after about $10^{6}$ shots (energy $1-5 \mathrm{~J} /$ pulse). The white disk at the bottom is the Teflon high-voltage feedthrough insulator, with a special profile to increase the surface flashover voltage [see Fig. 2(a)].

$$
\nu=\frac{p_{2}}{p_{1}} \cdot \frac{F}{A}
$$

in which $p_{1}$ is the spark-gap pressure, $p_{2}(=1$ bar $)$ is the pressure at the exhaust of the switch (where the flow rate measurements were performed), $F$ is the flow rate $\left[\mathrm{m}^{3} / \mathrm{s}\right]$, determined by measuring the time required to fill a fixed volume to atmospheric pressure with the exhaust gas of the switch, and A $\left(=3.96 \cdot 10^{-4} \mathrm{~m}^{2}\right)$ is the flow cross section in the gap (between electrodes and trigger).

The power consumed by the air compressor to maintain the forced gas flow can be calculated as the product of pressure drop over the switch $(\sim 0.2$ bar $)$ and gas flow rate. At the highest flow rates of $35 \mathrm{Nm}^{3} / \mathrm{h}$ this results in an energy consumption of around $200 \mathrm{~W}$.

In Fig. 6, the velocity pressure as function of pulse repetition rate dependency is shown. The markers indicate the conditions for which the switch fires directly after the charging has been completed. For conditions in the region below the markers, the switch may pre-fire. For conditions in the region above the markers, the switch will late-fire. Due to the smaller pressure region for $20 \mathrm{kV}$ average switching voltage (2.5-3.5 bars) only one velocity-pressure characteristic was measured. The obtained result, not shown in this article, was similar to the $34 \mathrm{kV}$ average switching voltage situation.

The results clearly demonstrate the beneficial use of both pressure and flow as stabilization method. For most pulse repetition rates, several combinations of pressure and flow rate exist. For continuous operation it is preferred to use a large air-flow rate, to remove the evaporated electrode material from the gap, preventing it from accumulating inside the switch or on the insulators. Furthermore, according to Persephonis et al. ${ }^{13}$ although the inductance of the switch decreases for decreasing gap distance and increasing gas pressure, for a fixed gap distance an increase in pressure results in an increase in inductance.

\section{B. Time-delay, jitter, stability and lifetime measurements}

To demonstrate the long-time stability of the switch in combination with the resonant charging unit, the system was 
continuously run for $2.5 \mathrm{~h}$ at $100 \mathrm{pps}$ and $0.75 \mathrm{~J} /$ pulse. An average measurement of 1000 pulses was preformed every minute. The obtained average switching voltage over the complete time period was $34.4 \mathrm{kV}$, and its standard deviation (expressed as percentage of the average voltage) is $0.7 \%$.

Another interesting topic for switches is the switching time delay and its jitter. Because the breakdown process is statistical in nature, the time between complete charging of the anode and closing of the switch varies (time delay). When monitoring a large number of shots the time delay distribution will become "bell" shaped. The width of this shape, measured at half the maximum value (FWHM), is used as a measure for the time jitter.

For the measurements shown in Fig. 7, the maximum pulse repetition rate was limited to $280 \mathrm{pps}$. Above this frequency the time jitter became too large to be able to perform correct measurements. For a fixed pulse repetition rate the time delay and jitter were influenced by changing gas pressure and flow rate. However, only situations without pre-fire were measured (in other words, the jitter is always less than or equal to the time delay). Clearly, for higher repetition rates the time delay and jitter have similar values. Late firing cannot be observed anymore, only firing directly or shortly after the charging is completed.

Measurements regarding the lifetime of the switch have not yet been performed, since this can only be done after a large number of shots (mass difference measurement). However, an estimate of the electrode lifetime of the switch can be made, using the following assumptions:

(1) According to Koutsoubis and MacGregor, ${ }^{12}$ the erosion rate for brass is $\sim 8 \cdot 10^{-6} \mathrm{~cm}^{3} / \mathrm{C}$. For $10 \mathrm{~J}, 60 \mathrm{kV}$, $100 \mathrm{~ns}$ pulses this results in $10^{-9} \mathrm{~cm}^{3} /$ shot.

(2) The effect of the "moving arc" mechanism on the erosion rate has not been taken into account, because at the moment no quantitative data of this effect on erosion rate is available. Nevertheless, the mechanism is believed to be capable of reducing the erosion rate considerably.

(3) The electrode erosion is uniform (Fig. 8).

(4) The erosion rates for anode, cathode and trigger electrode are equal.
(5) A layer with a thickness of about $2 \mathrm{~mm}$ is allowed to evaporate before the electrodes cannot be used anymore. During the increase in inter electrode distance, the pressure has to be decreased, to maintain stable switching performance.

Using the information from Table II it can be calculated that about $40 \mathrm{~cm}^{3}$ of electrode material (for one electrode) is allowed to be evaporated. With the assumed erosion rate, the switch can be used up to $10^{10}$ shots, which is equal to a total charge transfer of $10^{6} \mathrm{C}$ for the pulse conditions mentioned above.

\section{ACKNOWLEDGMENTS}

The project was supported by the Dutch IOP-EMVT project. The authors would like to thank Huub Bonne, Frans van Gompel and Ad van Iersel for their support.

${ }^{1}$ T. R. Burkes, J. P. Craig, M. O. Hagler, M. Kristiansen, and W. M. Portnoy, IEEE Trans. Electron Devices 26, 1401 (1979).

${ }^{2}$ S. A. Nair, Ph.D. thesis, Eindhoven University of Technology, 2004.

${ }^{3}$ G. J. J. Winands, K. Yan, S. A. Nair, A. J. M. Pemen, and E. J. M. van Heesch, Plasma Process. Polym. 2, 232 (2005).

${ }^{4}$ K. Yan, Ph.D. thesis, Eindhoven University of Technology, 2001.

${ }^{5}$ K. Yan, G. J. J. Winands, S. A. Nair, E. J. M. van Heesch, A. J. M. Pemen, and I. de Jong, J. Adv. Oxid. Technol. 7, 116 (2004).

${ }^{6}$ D. J. Biswas, J. P. Nilaya, and U. K. Chatterjee, Rev. Sci. Instrum. 69, 4242 (1998).

${ }^{7}$ J. M. Koutsoubis, S. J. MacGregor, and M. Turnbull, IEEE Trans. Plasma Sci. 27, 272 (1999).

${ }^{8}$ S. J. MacGregor, S. M. Turnbull, F. A. Tuema, and O. Farish, IEEE Trans. Plasma Sci. 25, 110 (1997).

${ }^{9}$ W. J. Thayer, V. C. H. Lo, and A. K. Cousins, 18 th IEEE Power Modulator Symposium, Hilton Head, SC, 20-22 June 1988, p. 257.

${ }^{10}$ S. L. Moran and L. W. Hardesty, IEEE Trans. Electron Devices 38, 726 (1991).

${ }^{11}$ J. M. Lehr, M. D. Abdalla, J. W. Bruger, J. M. Elizondo, J. Fockler, F. Gruner, M. C. Skipper, I. D. Smith, and W. D. Prather, 12th IEEE International Pulsed Power Conference, Monterey, CA, 27-30 June 1999, p. 1199.

${ }^{12}$ J. M. Koutsoubis and S. J. MacGregor, J. Phys. D 33, 1093 (2000).

${ }^{13}$ P. Persephonis, K. Vlachos, C. Georgiades, and J. Parthenios, J. Appl. Phys. 71, 4755 (1992).

${ }^{14}$ A. L. Donaldson, T. G. Engel, and M. Kristiansen, IEEE Trans. Magn. 25, 138 (1989).

${ }^{15}$ F. M. Lehr and M. Kristiansen, IEEE Trans. Plasma Sci. 17, 811 (1989). 